straints. In a paper by B. V. Dean (United States), on group research as an educational tool, the author discusses the advantages and disadvantages of group research (as distinct from research done by individual students). This will be of special interest to educationalists and others responsible for planning courses in which some form of applied research is an essential part of the curriculum. K. W. Webb (United States) reports on an exploratory operational research study of the United States national oceanographic programme, and makes the point that the experience that operational research has gained in the field of industrial management can be applied to good effect in the field of national management. He makes specific recommendations for work of an operational research nature to be continued in certain specific fields of oceanographic research. Perhaps one of his most important recommendations relates to the setting up of a scientific information system, with special attention to the information explosion that will take place because of continuous recording devices and sensor satellites. A paper by A. H. Rubenstein and M. Radnor (United States) deals with an investigation of the organization of research and development in decentralized companies and focuses attention on the relationship between top management and divisional management in the area of research and planning. Data from two field studies are presented. Finally, thore is a paper by B. T. Price (United Kingdom) on the national control of scientific and technical resources, which takes the form of a contribution by someone who has not specialized in operational research, but wishes to find out whether it can help in the difficult problem of managing research and development at Government level.

This small sample of the subject-matter and content of papers presented at the conference should serve to attract the interest of scientists who are not directly concerned with operational research.

S. J. Morrison

\section{SHAPE AND ARRANGEMENT IN LIPIDS}

\section{The Structure of Lipids by Spectroscopic and X-ray Techniques}

By D. Chapman. Pp. xii +323 . (London: Methuen and Co., Ltd., 1965.) 63s. net.

T has frequently been observed that the investigation of lipids, once carried out by only a few patient investigators, has been revolutionized during the past ten years by the application of chromatographic techniques in general and of thin-layer and gas-liquid chromatography in particular. These procedures have solved many of the problems of separation and isolation which all lipid investigators have to face, and in recent years rapid advances have been made on problems where progress had been slow and a beginning has been made on problems which previously could not be started. These important developments must not be allowed to overshadow the less spectacular, but nevertholoss important, developments recently made in our understanding of the shape and arrangement of the fascinating lipid molecules in crystals and in biological systems. Dr. D. Chapman has contributed to these advances and is well placed to describe for us the present situation.

Though it is now possible to isolate a lipid in a relatively pure state and to determino its structure and fatty-acid composition without too much difficulty, this tells us little about tho arrangement of lipid molecules in vitro or in vivo systems, and advances in this area have devoloped from the application of those spectroscopic and $\mathrm{X}$-ray methods which occupy the greater part of The Structure of Lipids by Spectroscopic and X-ray Techniques. It is made clear that there remain large areas of uncertainty and ignorance. This follows, for example, from the comparison between what is known about the long-chain acids and their simple glycerides and the paucity of information concerning the more complex lipids. It is, of course, in the nature of science to start with simple and controllable systems, and to move from these to more complicated systems. Dr. Chapman has placed us in his debt by summarizing so effectively the answers to the simpler (relatively speaking) questions and by indicating the more difficult questions which still have to be solved. It is to be hoped that he will provide a sequel when further advances have been made.

After a brief chapter outlining the field of lipids, Chapter 2 (29 pp.) is devoted to the major separation techniques, including the use of the ultracentrifuge for lipoproteins, counter-current distribution, and the usual battery of chromatographic procedures. It seems to me that this chapter could have been omitted without serious loss. Apart from the final chapter ("Future Developments and Other Techniques", $5 \mathrm{pp}$.), the remainder of the book consists of six chapters covering the use of five spectroscopic techniques and of X-ray erystallography. The space given to each topic (ultra-violet spoctroscopy, $15 \mathrm{pp}$.; infra-red and Raman spectroscopy, 81 pp.; mass spectrometry, 47 pp.; nuclear magnetic resonance spectroscopy, $48 \mathrm{pp}$; electron spin resonance spectroscopy, $13 \mathrm{pp}$; and X-ray diffraction, $95 \mathrm{pp}$.) reflects the present-day value of these various tochniques. In each of these chapters a deseription of the basic theory is followed by a brief account of the experimental technique. Thereafter its application to carboxylic acids and rolated aliphatic compounds, glycerides, and, where relevant, sterol ester's, phospholipids and other complex lipids, is described.

Figures and tables aro liberally distributed throughout the book and add considerably to its value. Selected references are given at the end of each chapter and the index seems adequate but not over-long. Only a few minor errors were noted. There is no doubt in my mind that this is a valuable addition to lipid literature which chemists, biologists and medical men will want to have and will consult frequently. $\quad$ F. I). Gunstone

\section{COGNITIVE DEVELOPMENT OF THE YOUNG CHILD}

The Early Growth of Logic in the Child

Classification and Seriation. By Bärbel Inhelder and Jean Piaget. Translated from the Fronch by E. A. Lunzer and D. Papert. Pp. xxv + 302. (London: Routledge and Kegan Paul, Ltd., 1964.) 40s. net.

7 HE gulf which, for forty years, has separated the work of Jean Piaget from the mainstream of psychological thought in the United States and in Britain is at last being bridged. Evidence of this is to be found in the new books which are appearing in Britain and in the United States, summarizing Piaget's work so far and attempting to synthesizo it with recent developments in Ameriean and British psychology; and in Piagot's attempt to take account of the objections which are commonly, if sometimes rather uncomprehendingly, made to his methodology.

In such a context, translations of recent books by Piaget are to be welcomed, ospecially when the translation is of an unusually high standard and the book itself makes an important contribution to Piaget's thoory of cognitive development. Not that 'The Early Growth of Logic in the Child is an easy book to read, even in its elegant translation. Nor does it make a good introduction to Piaget's work. (It is far too specialized for that, and the rocent American texts by J. MeV. Hunt and J. H. Flavellread in that order-make a better introduction than anything written by Piaget himself.) But it is an important book since it provides a highly detailed description and explanation of the ways in which, according to Piaget, the logical processes of classification and seriation develop 